\title{
Using Wi-Fi Data Link to Create the Navigation Situation Monitoring and Ship Control System
}

\author{
I. Afonin, V. Iskiv, Y. Mickhayluck, A. Schekaturin, I. Skorik \& E. Redkina \\ Sevastopol State University, Sevastopol, Russia
}

\begin{abstract}
The article considers methods for constructing systems for remote monitoring of the navigation situation and the state of ship control systems. Variants of building a system for remote monitoring of the navigation situation and the state of control systems of the ship have been developed; hardware implementation of the monitoring system has been developed, parts of which are the nodes of the local network. Wireless network model of the system has been developed. A stand of the on-board part of the monitoring system was developed and manufactured, its experimental study was carried out, which confirmed the effectiveness of the solution used. Modeling of the coverage areas of the system for various conditions of using the monitoring system has been performed.
\end{abstract}

\section{INTRODUCTION}

At present, much attention is paid to the development of remote monitoring systems for the navigational situation and the state of ship control systems, since with the current level of development of telecommunication systems and the functionality of ship complexes and assemblies, the ability to remotely monitor the navigation situation and the condition of ship control systems can significantly increase the efficiency of solutions data vessels practical tasks.

From the latest developments in this area, several of the most significant technical solutions can be distinguished.

So, the known monitoring system for moving objects "Impulse-GLONASS / GPS: Water Transport", which allows monitoring of small vessels [1]. The monitoring system for moving objects is built on a modular basis.
Monitoring systems are known that make it possible to monitor the condition of ship units and to remotely control their operation.

In particular, Altair LLC offers a software and hardware complex for a ship monitoring system designed for automated monitoring of a ship's power plant and monitoring the location of river and mixed (river-sea) vessels [2].

Transas vessel traffic control systems are modern automated systems used to improve the safety of navigation, the safety of life at sea and protect the environment from possible negative consequences of shipping, as well as improve the efficiency of navigation and cargo transportation [3]. Ship traffic control systems provide users with a variety of navigation information, allow the identification and tracking of ships and other navigation objects in terrestrial waters, and also plan shipping in terrestrial waters. 
In the field of electronic navigation, global improvements are also underway. For example, the International Maritime Organization is developing and implementing the concept of e-Navigation. The concept involves improving the safety of shipping all over the world through the active use of modern technologies, increasing the information support of ships and terrestrial services, and improving the exchange of navigation data between them [4].

In 2013, the Russian company ZAO KB NAVIS developed and certified in the marine and river shipping registers a shipborne GNSS GLONASS / GPS combined receiver-indicator type SN-5703 with a monitoring function [5]. A distinctive feature of the transceiver is the ability to build on its basis monitoring systems for sea and river vessels of various sizes and internal organization, suitable for a small number of special purpose ships, and integration into existing global coverage monitoring systems, both departmental and public companies.

The currently used systems for monitoring the navigational situation and the state of the ship's control systems have, as a rule, a low-speed communication channel between the ship and terrestrial subsystems or are characterized by significant complexity and cost, as well as narrow specialization, therefore, the urgent task is to develop a system for remote monitoring of the navigational situation and condition ship control systems having a high-speed data channel that allows streaming video transmission.

\section{BLOCK DIAGRAM OF REMOTE MONITORING OF NAVIGATION SITUATION AND STATE OF VESSEL CONTROL SYSTEMS}

The remote monitoring system of the navigation situation and the state of the ship's control systems should transmit from board to shore information about the state of the ship's equipment, the readings of ship instruments, as well as video information about the situation around the ship and audio information from external and internal microphones. Onshore, this information should be displayed in a form that is convenient and familiar to the operator.

The structural diagram of the remote monitoring system of the navigation situation and the state of the ship control systems should have a terrestrial subsystem and an onboard (ship) subsystem communicating via a communication channel, as shown in Figure 1.

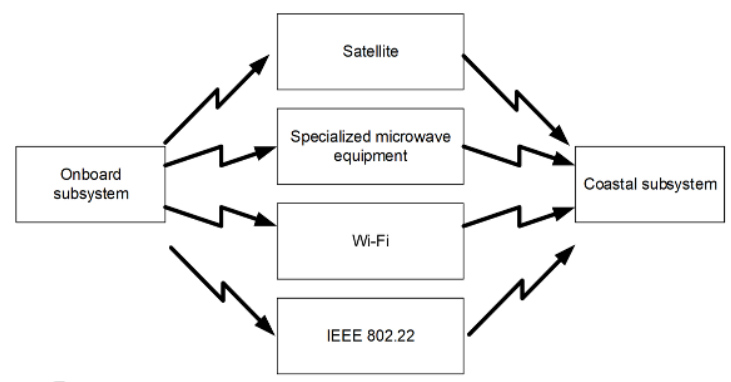

Figure 1. Block diagram of a system with different communication channels.
3 ON-BOARD SUBSYSTEM OF THE REMOTE MONITORING SYSTEM

The onboard subsystem should have the following elements:

- shaper of group information signal, which converts heterogeneous signals from all systems of the vessel into a single group digital signal;

- a modem that generates a signal with a given type and modulation parameters for transmission through the communication channel and demodulates the signal received from the communication channel;

- a control computer that transmits the generated group information signal to the modem and receives

- a signal from the modem for transmission to the driver of the control signals.

The block diagram of the onboard subsystem is shown in Figure 2.

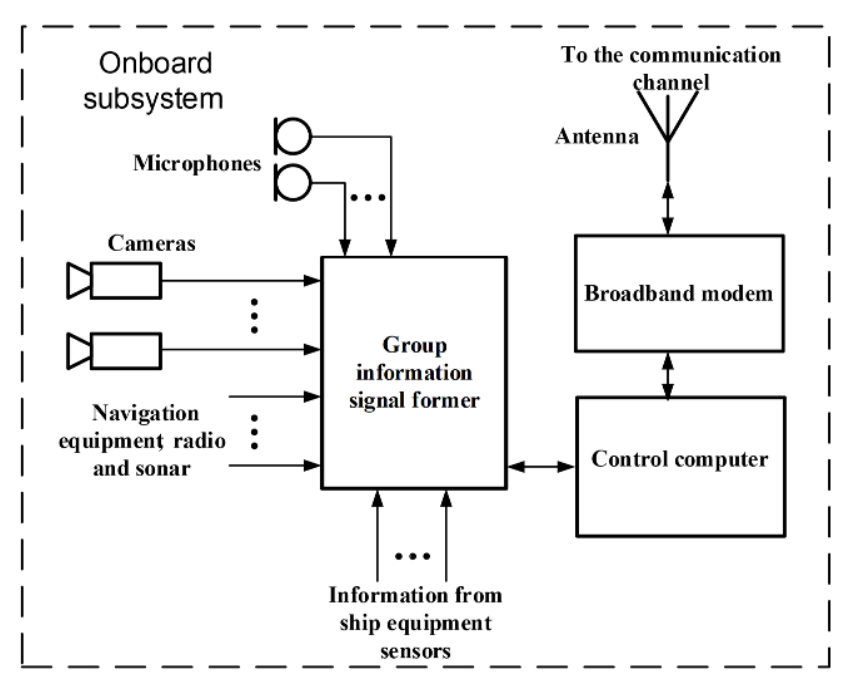

Figure 2. Block diagram of the onboard subsystem.

The group information signal generator is a set of adapters that converts digital signals into discrete or analog signals of the required amplitude and power for discrete or proportional (analog) control of actuators (relays, motors, etc.). The block diagram of this unit depends on the composition of the equipment and will be different for each vessel.

It is possible to use an integrated ship bridge. In this case, a remote control system can be used, most of the signals are already brought to the same interface and standard, and a specialized controller with an interface converter is used as a shaper of the group information signal.

A data recorder can be used as a shaper of a group information signal. In this case, most sensors are equipped with the necessary adapters, and their signals are grouped into a single digital stream, which is recorded by the recorder. The functional diagram of the group information signal shaper is shown in Figure 3.

Data recorders are equipped with the necessary network interfaces for connecting to control computers and modems. 
The signals from sensors equipped with various interfaces in the interface converter are brought to a single digital form and then fed to the registration units and the group signal shaper.

The registration unit records the current information, saves it for a predetermined time interval and allows you to search and access it upon request.

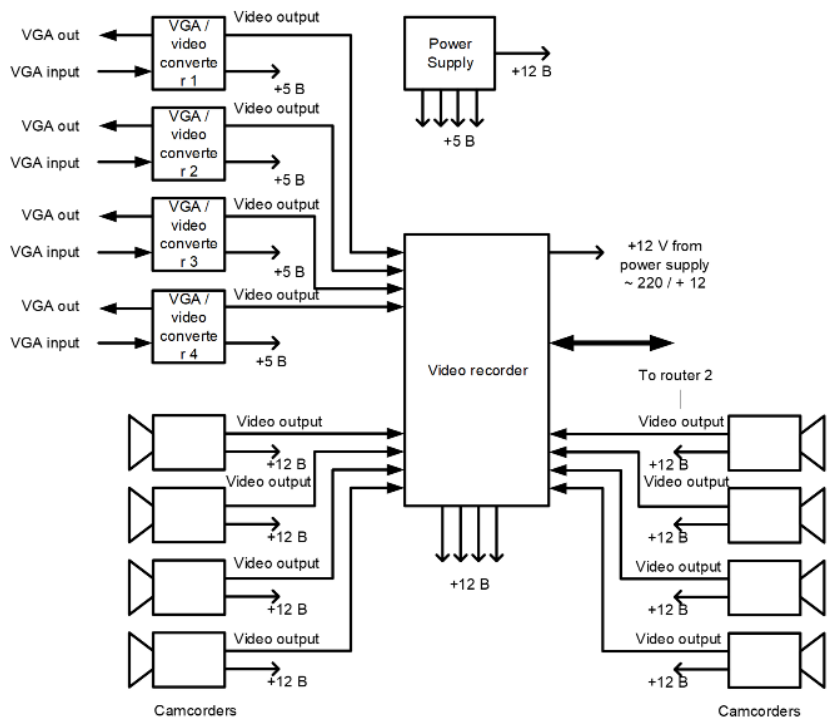

Figure 3. Group information signal shaper.

The group signal generator generates a signal of a uniform standard from heterogeneous digital signals, suitable for transmission, and sends this signal via the onboard transmitter to the terrestrial subsystem.

\section{TERRESTRIAL SUBSYSTEM OF REMOTE MONITORING SYSTEM}

The block diagram of the terrestrial subsystem is shown in Figure 4.

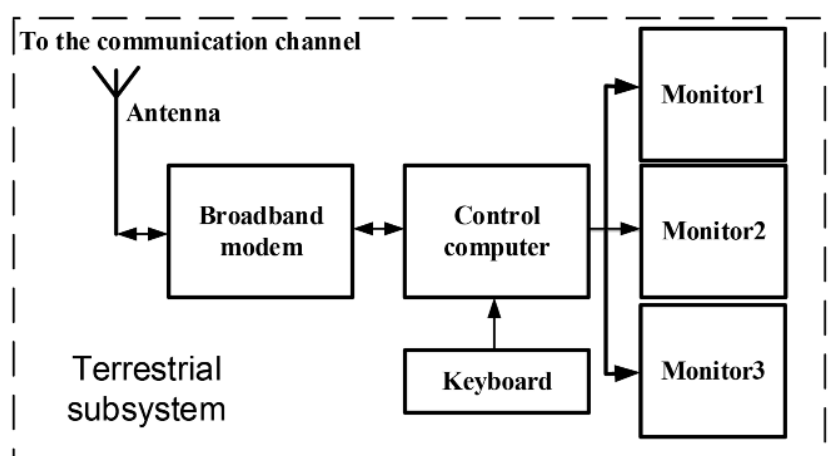

Figure 4. Block diagram of the terrestrial subsystem.

The subsystem uses several monitors, each of which displays its own type of information.

The terrestrial receiver receives the radio signals transmitted by the onboard subsystem, detects them and transmits to the group signal decoder.

The group signal decoder extracts individual components from the general group signal - video signals, audio signals, information signals from ship's sensors and transmits them to display, display and playback devices.

The video information display device displays on the screens information from video cameras and monitors of a ship's locator, navigation and other computers.

The audio information reproducing device reproduces sounds perceived by the microphones of the on-board subsystem.

The sensor status indicator displays the status of sensors of various ship systems and devices.

\section{MODELING THE OPERATION OF A SYSTEM FOR REMOTE MONITORING}

The simulation of the operation of the remote monitoring system of the navigational situation and the state of ship control systems was performed using the Cisco Packet Tracer software product. The main switching nodes of the network of the terrestrial and onboard system of the system are formed (see Figure 5), the IP addressing of the infocommunication network of the remote control system is developed, is presented in Table 1 - 2 .

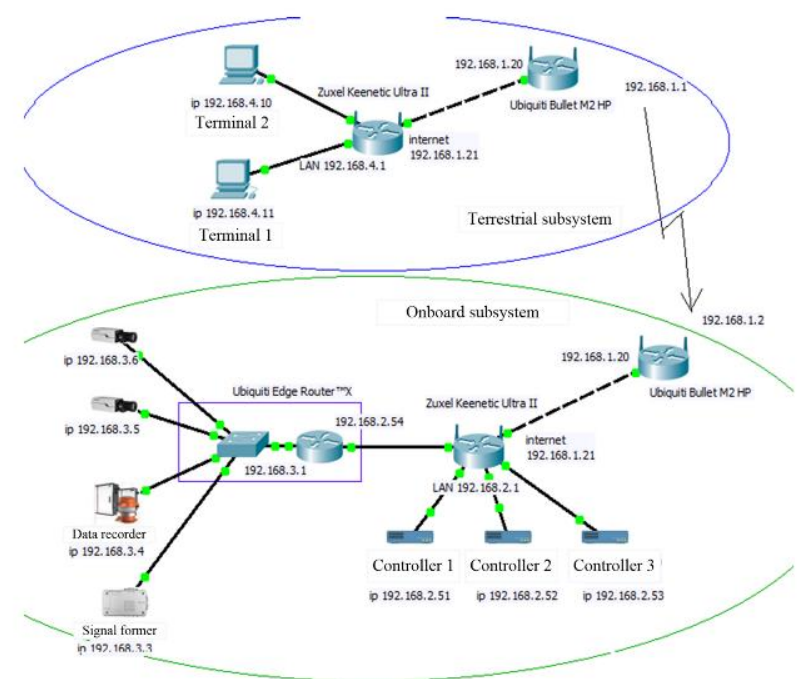

Figure 5. Wireless network model of a system for remote monitoring of the navigation situation and the status of ship control systems.

Table 1. IP addressing of the network of the onboard complex of the remote control system.

\begin{tabular}{ll}
\hline On-board system: & \\
\hline Ubiquiti & Bullet M2 HP Bridge 192.168.1.2 \\
& LAN gateway 192.168.1.20 (trunk) \\
Zuxel Keenetic & Ultra II Internet 192.168.1.21 (trunk) \\
LAN gateway & 192.168.2.1 (trunk) \\
Controller 1 & 192.168.2.51 (vlan 10) \\
Controller 2 & 192.168.2.52(vlan 10) \\
Controller 3 & 192.168.2.53(vlan 10) \\
Ubiquiti Edge & LAN gateway 192.168.2.54 (trunk) \\
$\quad$ RouterTMX & LAN gateway 192.168.3.1 (trunk) \\
IP Webcamera 1 & 192.168.3.6 (vlan 11) \\
IP Webcamera 2 & 192.168.3.5 (vlan 11) \\
Registrar & 192.168.3.4 (vlan 12) \\
Shaper & 192.168.3.3 (vlan 12) \\
\hline
\end{tabular}


Table 2. IP addressing of the network of the terrestrial complex of the remote control system.

\begin{tabular}{|c|c|}
\hline \multicolumn{2}{|c|}{ Terrestrial system: } \\
\hline Ubiquiti Bulle & $\begin{array}{l}\text { P Bridge 192.168.1.1 } \\
\text { LAN gateway 192.168.1.20 (trunk) }\end{array}$ \\
\hline Zuxel Keeneti & IIInternet 192.168.1.21 (trunk) \\
\hline LAN gateway & 192.168.4.1 (trunk) \\
\hline Terminal 1 & 192.168.4.10 \\
\hline Terminal 2 & 192.168.4.11 \\
\hline
\end{tabular}

To simulate Ubiquiti Edge Router ${ }^{\mathrm{TM}} X$ in a network emulator, two network nodes are used: a switch and a router.

Settings of the Zuxel Keenetic Ultra II router of the terrestrial system: Internet Setup IP address 192.168.1.21, subnet mask 255.255.255.0, Gateway default 192.168.1.20; Network Setup IP address 192.168.4.1, subnet mask 255.255.255.0, security type WPA2 Personal, AES encryption.

Settings for the Zuxel Keenetic Ultra II router onboard system: Internet Settings - IP address 192.168.1.21, subnet mask 255.255.255.0, LAN Settings - IP address 192.168.2.1, subnet mask 255.255.255.0; Wireless Settings - channel 6, WPA2-PSK authentication, AES encryption.

\section{SIMULATION OF COVERAGE AREAS}

Based on the analysis of the characteristics of communication systems, we will determine the initial data for modeling the marine communication channel of the remote monitoring system of the navigation situation and the status of the ship control systems:

- frequency $2.4 \mathrm{GHz}$;

- transmitter output power $1 \mathrm{~W}$;

- the sensitivity of the receiver at a transmission rate of $24 \mathrm{Mb} / \mathrm{s}$ is $83 \mathrm{dBm}$; at a transmission rate of 54 $\mathrm{Mb} / \mathrm{s}$, it is $-75 \mathrm{dBm}$.

The results of simulation the coverage areas using directional antennas and different heights of elevation of antennas are shown in Figures 6-10.

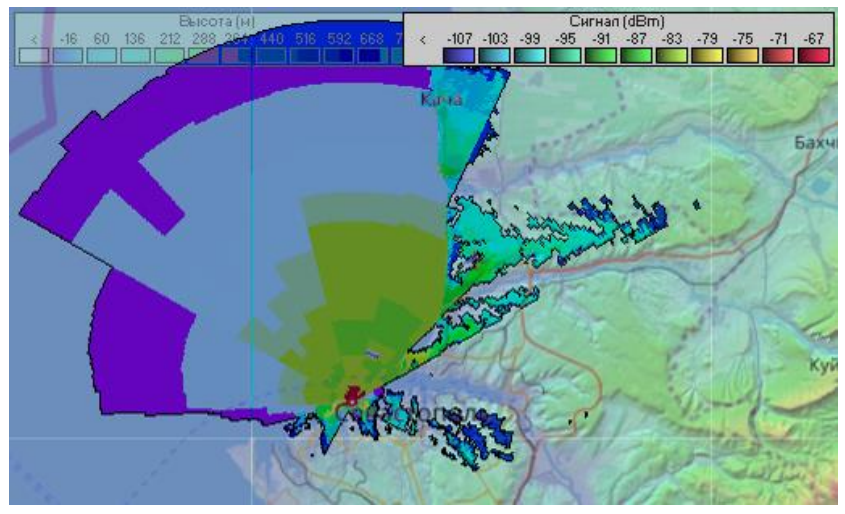

Figure 6. Height above sea level is 11 meters, antenna lifting height is 2 meters, directed antennas.

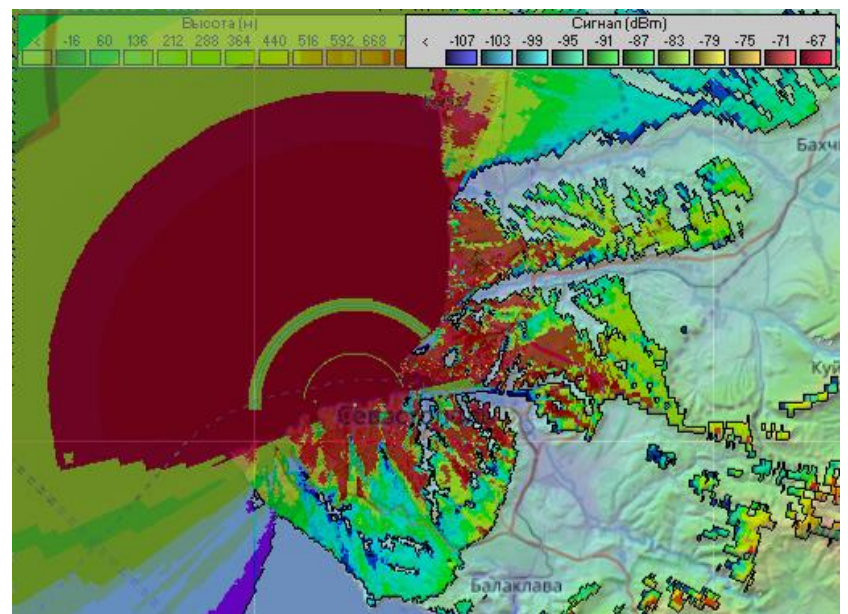

Figure 7. Height above sea level is 11 meters, antenna lifting height is 15 meters, directed antennas.

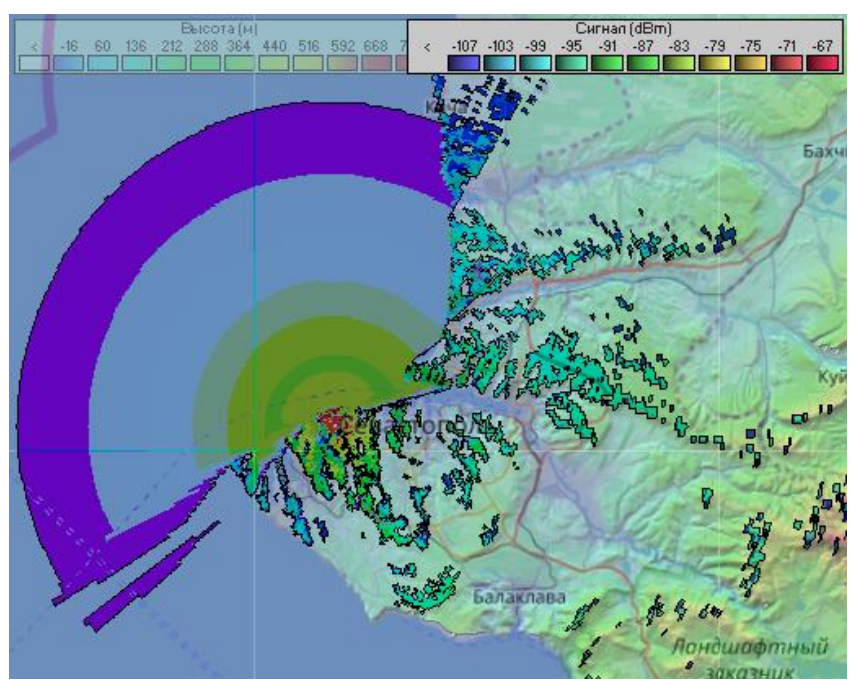

Figure 8. Height above sea level is 20 meters, antenna lifting height is 2 meters, directed antennas.

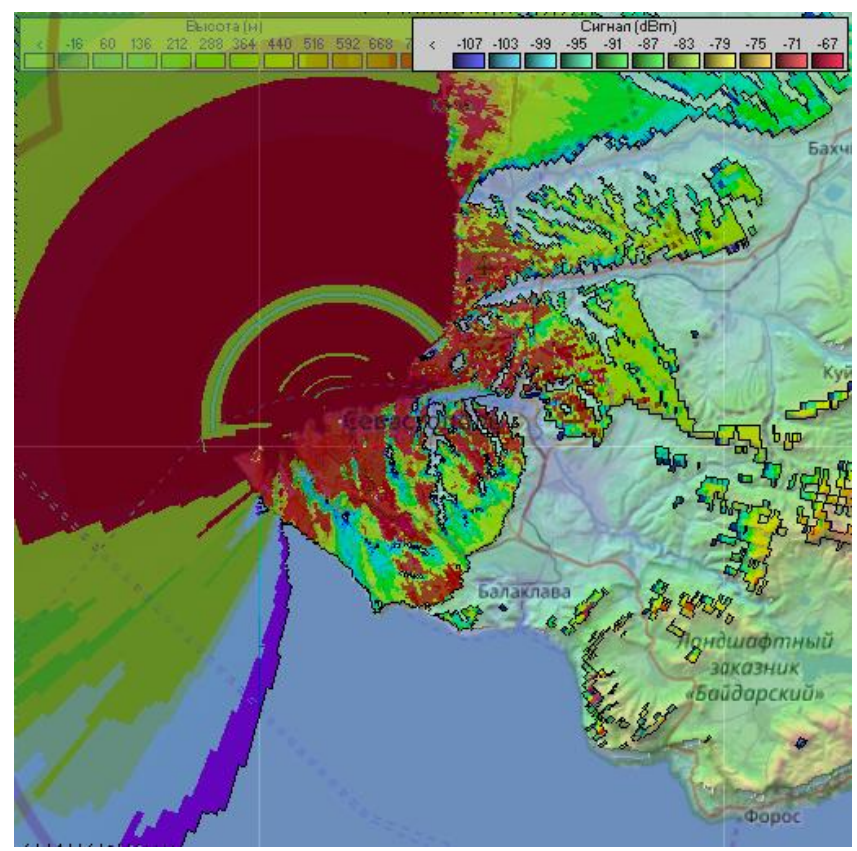

Figure 9. Height above sea level is 20 meters, antenna lifting height is 15 meters, directed antennas. 


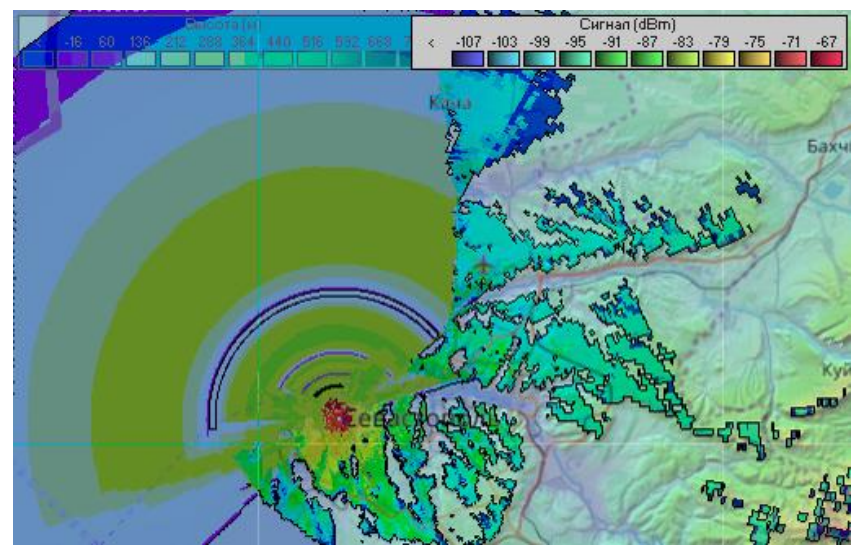

Figure 10. Height above sea level is 20 meters, antenna lifting height is 15 meters, dipole antennas.

\section{EXPERIMENTAL RESEARCH}

The stand was developed using a Wi-Fi data channel.

Onshore and onboard subsystems use MaxLink 01VS-M15 Wi-Fi antennas, Ubiquiti Bullet M2 HP Wi-Fi adapters and routers (Zuxel Keenetic Ultra II). Ubiquiti POE-24-24W-G are used as POE injectors for Bullet M2 HP.

The blocks for decoding, generating control signals, displaying video information, playing audio information, indicating the status of sensors are implemented on the basis of computers and their peripheral devices.

In the on-board subsystem, the EMV-800HD video recorder was used. The signal conditioning unit also includes VGA-AV (VGA to VIDEO) video converters, which allows you to convert the usual standard VGA (D-sub) signal, which is used in almost all monitors of marine radar, navigation, sonar, etc. systems into a video signal Video standard PAL or NTSC to register this signal with the DVR.

The onboard subsystem also includes three STM32F746 Discovery controllers. These controllers are used to organize the management of on-board systems and systems, for which interface blocks are also provided that support CAN Bus and Ethernet.

The high-performance Ubiquiti Edge Router ${ }^{\mathrm{TM}} \mathrm{X}$ router allows you to connect a number of peripheral devices and a signal conditioning unit to the on-board subsystem.

The image from the video cameras was transmitted from the onboard subsystem of the stand to the video cameras of the terrestrial subsystem and made it possible to track the movement of ships in the Streletskaya bay of Sevastopol. According to the measurement results at distances from $850 \mathrm{~m}$ to $3 \mathrm{~km}$, the total data transfer rate was from $4.7 \mathrm{Mbit} / \mathrm{s}$ to 0.9 Mbit/s.

The test bench of the onboard subsystem is shown in the figure 11 .

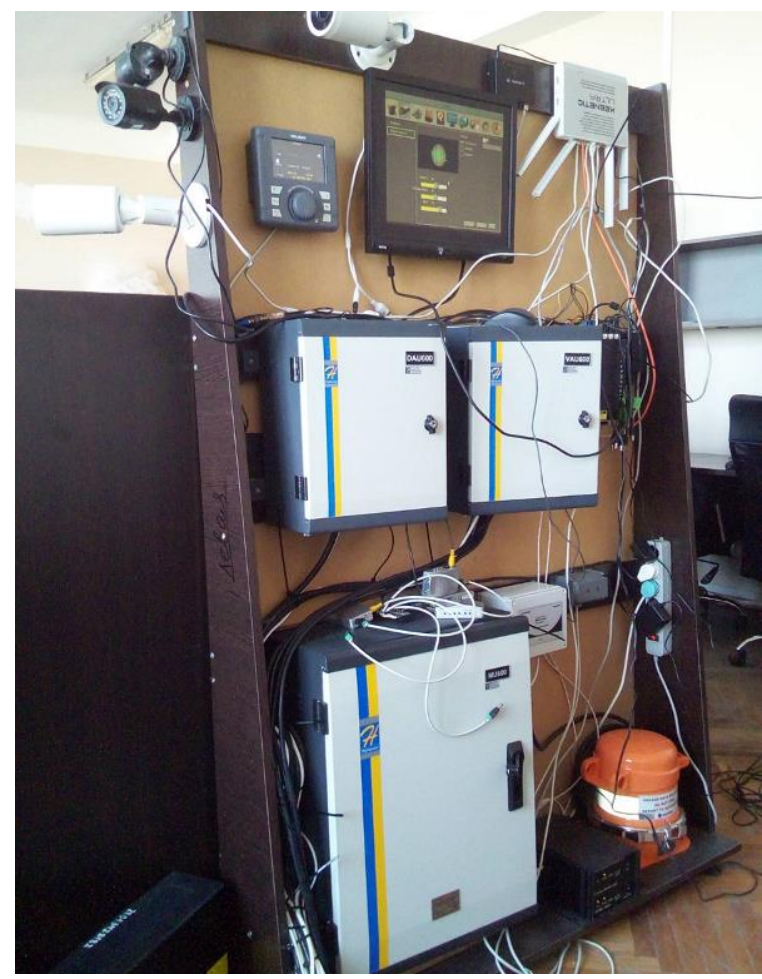

Figure 11. Test bench of the onboard subsystem.

\section{CONCLUSION}

The developed system allows monitoring the navigational situation, including by transmitting video information from the ship, and the status of the small ship control systems at a distance of several kilometers from the coast subsystem when using a Wi-Fi data channel and thousands of kilometers when using satellite communication channels. The developed monitoring system can be part of the crewless ship management system. The system is simple and very flexible due to the inclusion of system elements as nodes of a local network and the use of programmable controllers, which allows you to change the composition and purpose of the system parts. The monitoring system provides a data transfer rate sufficient to transmit video data from cameras installed on the ship.

\section{REFERENCES}

[1] The monitoring system for moving objects "ImpulseGLONASS / GPS: Water Transport" for the management of water transport, http://24glonass.ru/solutions/vodnyy-transport/vodnyytransport

[2] Control of sea and river transport, https://www.sirius.su/catalog/glonass-gpstrackery/otraslevye-resheniya/shipenergy

[3] Ship traffic control http://www.poseidon.su/products/suds.html

systems,

[4] Ship monitoring systems in the concept of E-Navigation Speaker: Milyakov D.F. VII International Forum "Communications on the sea and river - 2011", https://officemagazine.ru/auto/50372

[5] Milyakov D.F. Testing SN-5703 for monitoring ships, https://www.korabel.ru/news/comments/aprobaciya_sn5703_dlya_monitoringa_sudov.html 